\title{
Association of endothelial nitric oxide synthase polymorphisms with coronary artery disease in Korean individuals with or without diabetes mellitus
}

\author{
JEEHYEON BAE ${ }^{1,3^{*}}$, IN JAI KIM ${ }^{2 *}$, SEUNG HO HONG ${ }^{4}$, JUNG HOON SUNG ${ }^{2}$, SANG WOOK LIM ${ }^{2}$, \\ DONG HOON CHA ${ }^{2}$, YONG WOOK CHO ${ }^{2}$, DOYEUN OH ${ }^{1,2}$ and NAM KEUN KIM ${ }^{1,3}$ \\ ${ }^{1}$ Institute for Clinical Research, ${ }^{2}$ Department of Internal Medicine, School of Medicine, \\ and ${ }^{3}$ Department of Biomedical Science, CHA University, Seongnam; \\ ${ }^{4}$ Department of Science Education, Teachers College, Jeju National University, Jeju, Korea
}

Received March 16, 2010; Accepted May 4, 2010

DOI: 10.3892/etm_00000111

\begin{abstract}
Polymorphisms of the endothelial nitric oxide synthase $(e N O S)$ gene have been implicated in various diseases, but their roles as risk factors in type 2 diabetes mellitus (T2DM) with regard to coronary artery disease (CAD) are largely unknown. Therefore, we investigated the association of the genotypes and haplotypes of eNOS polymorphisms in CAD with T2DM. A case-control study was performed to evaluate the genotypes and haplotypes of the eNOS polymorphisms $(-786 \mathrm{~T}>\mathrm{C}, 4 \mathrm{a} 4 \mathrm{~b}$ and $894 \mathrm{G}>\mathrm{T})$ in $192 \mathrm{CAD}$ patients and 196 controls. The same population was also re-organized upon the status of T2DM. The genotypes of eNOS -786T $>\mathrm{C}, 4 \mathrm{a} 4 \mathrm{~b}$ and $894 \mathrm{G}>\mathrm{T}$ polymorphisms were determined by polymerase chain reaction-restriction fragment length polymorphism. We found that eNOS -786TC+CC and $4 \mathrm{a} 4 \mathrm{~b}+4 \mathrm{a} 4 \mathrm{a}$ genotypes were significantly prevalent in the diabetic controls and the diabetic CAD patients compared to the non-diabetic controls or non-diabetic CAD patients, respectively. The frequency of the -786C-4a-894G haplotype was significantly greater in the diabetic CAD patients $(\mathrm{p}=0.001)$ and diabetic controls $(\mathrm{p}=0.023)$ compared to the non-diabetic controls, whereas the haplotype of -786T-4b-894G was less prevalent in the diabetic CAD patients compared to the non-diabetic controls ( $\mathrm{p}=0.018)$. Significant associations of the genotypes and the haplotypes were consistently observed in the T2DM group compared to non-DM group, regardless of CAD status. Our finding suggests that the eNOS -786T $>\mathrm{C}$ and $4 \mathrm{a} 4 \mathrm{~b}$ polymorphisms and the $-786 \mathrm{C}-4 \mathrm{a}-894 \mathrm{G}$ haplotype are risk factors for T2DM, whereas
\end{abstract}

Correspondence to: Dr Nam Keun Kim, Institute for Clinical Research, Bundang CHA Medical Center, School of Medicine, CHA University, 351 Yatap-dong, Bundang-gu, Seongnam 463-712, Korea E-mail:nkkim@cha.ac.kr

*Contributed equally

Key words: coronary artery disease, endothelial nitric oxide synthase, haplotype, polymorphism, type 2 diabetes mellitus the haplotype of -786T-4b-894G has a protective effect against the development of T2DM.

\section{Introduction}

Endothelial dysfunction plays a crucial role in the initiation and progression of atherogenesis, and the presence of endothelial dysfunction predicts the presence of coronary artery disease (CAD) and provides prognostic information $(1,2)$. Factors including smoking, diet, aging and various diseases affect the proper function of the endothelium (3), and genetic predisposition also imposes considerable risk for the development of atherosclerosis (4), as polymorphisms of an increasing number of genes have been associated with cardiovascular diseases.

The endothelium plays an essential role in maintaining vascular tone and blood pressure through its production of nitric oxide (NO). The cardioprotective roles of $\mathrm{NO}$ include the inhibition of platelet aggregation, leukocyte adhesion and smooth muscle cell proliferation, the prevention of lowdensity lipoprotein (LDL) oxidation and its antioxidant effects (5-9). Thus, reduced bioavailability of NO is common to CAD, and defects in NO production and function correlate well with the incidence of CAD. NO is produced from 1-arginine by endothelial nitric oxide synthase (eNOS), and decreased expression of eNOS has been observed in human atherosclerotic vessels (10).

Polymorphisms of the eNOS gene have been observed in various populations. A single nucleotide polymorphism (SNP), $-786 \mathrm{~T}>\mathrm{C}$, involving a substitution of thymine $(\mathrm{T})$ to cytosine (C) was identified in the 5'-flanking region of eNOS at a locus 786 base-pairs (bp) upstream of the first exon (11). Another common variant of eNOS has also been described with a G-to-T transversion at nucleotide position 894 (894G>T) leading to a change of amino acid 298 (Glu298Asp) (12). A 27-bp repeat polymorphism in intron 4 of the eNOS gene (eNOS 4a4b) has also been reported (13).

Numerous studies have analyzed the association of eNOS polymorphisms and cardiovascular diseases, but no solid conclusions have been drawn, partly due to the discrepancies 
Table I. Demographic and clinical characteristics of coronary artery disease (CAD) patients and controls with or without diabetes mellitus (DM).

\begin{tabular}{|c|c|c|c|c|c|c|}
\hline \multirow[t]{2}{*}{ Characteristics } & \multicolumn{3}{|c|}{ Subjects without CAD } & \multicolumn{3}{|c|}{ Subjects with CAD } \\
\hline & $\begin{array}{l}\text { Controls non-T2DM } \\
\qquad(\mathrm{n}=161)\end{array}$ & $\begin{array}{l}\text { Subjects T2DM } \\
\qquad(n=35)\end{array}$ & $\mathrm{p}$-value & $\begin{array}{l}\text { Controls non-T2DM } \\
\qquad(\mathrm{n}=138)\end{array}$ & $\begin{array}{l}\text { Subjects T2DM } \\
(n=54)\end{array}$ & $\mathrm{p}$-value \\
\hline Male, n (\%) & $78(48.4)$ & $22(62.9)$ & 0.138 & $79(57.2)$ & $32(59.3)$ & 0.871 \\
\hline Age $^{\mathrm{b}}$ (years) & $59.78 \pm 11.04$ & $61.29 \pm 11.09$ & 0.467 & $59.70 \pm 12.53$ & $62.02 \pm 11.33$ & 0.239 \\
\hline Smoking, n (\%) & $11 \quad(6.8)$ & $7(20.0)$ & 0.023 & $55(39.9)$ & $25(46.3)$ & 0.421 \\
\hline Hyperlipidemia, n (\%) & $19(11.8)$ & $15(42.9)$ & $<0.0001$ & $23(16.7)$ & $14(25.9)$ & 0.157 \\
\hline Hypertension, n (\%) & $79(49.1)$ & $24(68.6)$ & 0.041 & $71(51.4)$ & $38(70.4)$ & 0.023 \\
\hline
\end{tabular}

${ }^{a} \mathrm{p}$-values were estimated using the independent $\mathrm{t}$-test for continuous data and the Fisher's exact test for categorical data. ${ }^{\mathrm{b}}$ Values (years) are means \pm SD.

among studies and the lack of a reliable marker of eNOS gene function in humans (14). At present, only a few reports are available that assess the predispositions of eNOS genotypes to type 2 diabetes mellitus (T2DM), although many have investigated their associations to diabetic complications. NO is known to modulate peripheral and hepatic glucose metabolism and insulin secretion (15), and diabetes mellitus (DM) is a known risk factor for CAD (16). Thus, in the present study, we assessed the $e N O S$ genotype distribution of the three polymorphisms, $-786 \mathrm{~T}>\mathrm{C}, 4 \mathrm{a} 4 \mathrm{~b}$ and $894 \mathrm{G}>\mathrm{T}$, in CAD patients and controls, with regard to T2DM status, and performed haplotype analyses of three-loci eNOS polymorphisms.

\section{Materials and methods}

Subjects. In this study, we enrolled 192 CAD patients (including 54 T2DM patients) and 196 control subjects without CAD (including 35 T2DM patients) (Table I). CAD patients, who presented at the Cardiology Department of the Bundang CHA Medical Center from November 2003 to June 2005 by consecutive referral, were recruited. During coronary angiography, patients with at least one major coronary artery showing $>50 \%$ stenosis were categorized as CAD patients. T2DM was defined as a fasting plasma glucose $>126 \mathrm{mg} /$ dl (7.0 mmol/l) (17) and included patients taking diabetes medication. Hypertension was defined as systolic pressure $>140 \mathrm{mmHg}$ and/or diastolic pressure $>90 \mathrm{mmHg}$ on more than one occasion, according to the Joint National Committee (JNC 7) report guidelines (18) and the current ingestion of hypertension medication. Smoking indicates current smoking.

As control subjects, we selected gender- and age-matched healthy individuals from those who presented at the Bundang CHA Medical Center for a health examination during the same period; these individuals had no history of myocardial infarction or cerebrovascular disease. The Institutional Review Board (IRB) of Bundang CHA Medical Center approved this genetic study in October 2003. All patients and controls were Korean and gave informed consent prior to enrollment in the study.

Genotype analysis. Genomic DNA was extracted from peripheral blood leukocytes using the G-DEX blood extraction kit
(Intron Inc., Seongnam, Korea). Nucleotide changes were determined by polymerase chain reaction (PCR)-restriction fragment length polymorphism analyses using the isolated genomic DNA as a template. The PCR for the -786T $>$ C polymorphism was performed using the following primers: 5'-ATG CTC CCA CCA GGG CAT CA-3' and 5'-GTC CTT GAA TCT GAC ATT AGG G-3'. DNA was amplified for 35 cycles of denaturing at $94^{\circ} \mathrm{C}$ for $30 \mathrm{sec}$, annealing at $51^{\circ} \mathrm{C}$ for $40 \mathrm{sec}$ and extension at $72^{\circ} \mathrm{C}$ for 40 sec. The PCR products were detected by gel electrophoresis after incubation with a restriction endonuclease, NgoMIV (New England Biolabs, Beverly, MA, USA) at $37^{\circ} \mathrm{C}$ for $16 \mathrm{~h}$. The primer sequences to detect the eNOS intron 4 polymorphism were 5'-AGG CCC TAT GGT AGT GCC TTT-3' and 5'-TCT CTT TAG TGC TGT GGT CAC-3'. DNA was amplified for 35 cycles of denaturing at $94^{\circ} \mathrm{C}$ for $1 \mathrm{~min}$, annealing at $49^{\circ} \mathrm{C}$ for $40 \mathrm{sec}$ and extension at $72^{\circ} \mathrm{C}$ for $40 \mathrm{sec}$. The PCR products were visualized by gel electrophoresis. The forward and reverse primers used to detect the $894 \mathrm{G}>\mathrm{T}$ polymorphism were 5 '-CAT GAG GCT CAG CCC CAG AAC-3' and 5'-AGT CAA TCC CTT TGG TGC TCA C-3', respectively. PCR reactions were run for 35 cycles: $95^{\circ} \mathrm{C}$ for $45 \mathrm{sec}, 63^{\circ} \mathrm{C}$ for $45 \mathrm{sec}$ and $72^{\circ} \mathrm{C}$ for $45 \mathrm{sec}$. The products were digested with the restriction endonuclease $\mathrm{Mbo}$ ( New England Biolabs) at $37^{\circ} \mathrm{C}$ for $16 \mathrm{~h}$ and detected by gel electrophoresis.

Statistical analysis. The clinical characteristics were compared by the Student's unpaired t-test. The distribution of genotypes for each polymorphism was assessed for deviation from Hardy-Weinberg equilibrium, and differences in genotype frequency and allele frequency between groups were assessed using $\chi^{2}$-tests. A value of $\mathrm{p}<0.05$ was considered statistically significant. StatsDirect Statistical Software version 2.4.4 (StatsDirect Ltd., Altrincham, UK) was used to calculate the odds ratio (OR) and 95\% confidence interval (CI). Haplotype analysis was performed using SNPAlyze ver.5.1 (Dynacom Co., Ltd., Yokohama, Japan).

\section{Results}

The demographic and clinical characteristics of the 192 CAD patients (including 54 T2DM patients) and the 196 controls 
Table II. eNOS genotype distribution and allele frequencies of coronary artery disease (CAD) patients and controls with or without diabetes mellitus (DM).

\begin{tabular}{|c|c|c|c|c|c|c|c|}
\hline \multirow[t]{2}{*}{ Genotype } & \multicolumn{3}{|c|}{ Controls without CAD } & \multicolumn{4}{|c|}{ Cases with CAD } \\
\hline & $\begin{array}{c}\text { Non-T2DM } \\
\quad(n=161)\end{array}$ & $\begin{array}{l}\text { T2DM } \\
(n=35)\end{array}$ & $\begin{array}{c}\mathrm{AOR}^{\mathrm{a}} \\
(95 \% \mathrm{CI})\end{array}$ & $\begin{array}{c}\text { Non-T2DM } \\
\quad(n=138)\end{array}$ & $\begin{array}{c}\text { AOR } \\
(95 \% \mathrm{CI})\end{array}$ & $\begin{array}{l}\text { T2DM } \\
(n=54)\end{array}$ & $\begin{array}{c}\text { AOR } \\
(95 \% \mathrm{CI})\end{array}$ \\
\hline \multicolumn{8}{|c|}{$e N O S-786 \mathrm{~T}>\mathrm{C}$} \\
\hline $\mathrm{TT}$ & $139(86.3)$ & $25(71.4)$ & 1.00 & $111(80.4)$ & 1.00 & $38(70.4)$ & 1.00 \\
\hline $\mathrm{TC}$ & $22(13.7)$ & $10(28.6)$ & $2.45(0.939-6.404)$ & $27(19.6)$ & $1.62(0.832-3.163)$ & $14(25.9)$ & $4.04(1.630-10.013)$ \\
\hline $\mathrm{CC}$ & $0 \quad(0.0)$ & $\begin{array}{ll}0 & (0.0)\end{array}$ & - & $0 \quad(0.0)$ & - & $2(3.7)$ & - \\
\hline $\mathrm{TC}+\mathrm{CC}$ & $22(13.7)$ & $10(28.6)$ & $2.45(0.939-6.404)$ & 27 (19.6) & $1.62(0.832-3.163)$ & $16(29.6)$ & $4.39(1.800-10.706)$ \\
\hline \multicolumn{8}{|l|}{ eNOS 4a4b } \\
\hline $4 b 4 b$ & $138(85.7)$ & $23(65.7)$ & 1.00 & $110(79.7)$ & 1.00 & $38(70.4)$ & 1.00 \\
\hline $4 a 4 b$ & $23(14.3)$ & $12(34.3)$ & $2.56(1.006-6.528)$ & $28(20.3)$ & $1.69(0.874-3.265)$ & $14(25.9)$ & $3.85(1.561-9.473)$ \\
\hline $4 \mathrm{a} 4 \mathrm{a}$ & $0 \quad(0.0)$ & $0 \quad(0.0)$ & - & $0 \quad(0.0)$ & - & $2(3.7)$ & - \\
\hline $4 a 4 b+4 a 4 a$ & $23(14.3)$ & $12(34.3)$ & $2.56(1.006-6.528)$ & $28(20.3)$ & $1.69(0.874-3.265)$ & $16(29.6)$ & $4.20(1.732-10.160)$ \\
\hline \multicolumn{8}{|c|}{$e N O S$ 894G $>\mathrm{T}$} \\
\hline GG & $131(81.4)$ & $32(91.4)$ & 1.00 & $114(82.6)$ & 1.00 & $43(79.6)$ & 1.00 \\
\hline GT & $30(18.6)$ & 3 (8.6) & $0.38(0.099-1.438)$ & $23(16.7)$ & $0.90(0.466-1.746)$ & $11(20.4)$ & $1.12(0.449-2.808)$ \\
\hline $\mathrm{TT}$ & $0 \quad(0.0)$ & $0 \quad(0.0)$ & - & $1 \quad(0.7)$ & - & $0 \quad(0.0)$ & - \\
\hline $\mathrm{GT}+\mathrm{TT}$ & $30(18.6)$ & 3 (8.6) & $0.38(0.099-1.438)$ & $4(17.4)$ & $0.91(0.473-1.764)$ & $11(20.4)$ & $1.12(0.449-2.808)$ \\
\hline
\end{tabular}

aOdds ratios (OR) were adjusted for age, gender, hypertension, hyperlipidemia and smoking status.

Table III. Haplotype analyses of three polymorphisms (-786T $>\mathrm{C}, 4 \mathrm{a} 4 \mathrm{~b}$ and $894 \mathrm{G}>\mathrm{T})$ of the eNOS gene from subgroups of coronary artery disease (CAD) patients and controls with or without diabetes mellitus (DM).

\begin{tabular}{|c|c|c|c|c|c|c|c|c|}
\hline \multirow[b]{2}{*}{ Haplotype $^{a}$} & \multicolumn{2}{|c|}{ Controls } & \multicolumn{2}{|c|}{ CAD } & \multirow[b]{2}{*}{$\mathrm{P} 1$} & \multirow[b]{2}{*}{$\mathrm{P} 2$} & \multirow[b]{2}{*}{ P3 } & \multirow[b]{2}{*}{$\mathrm{P} 4$} \\
\hline & Non-T2DM & $\mathrm{T} 2 \mathrm{DM}$ & Non-T2DM & T2DM & & & & \\
\hline $\mathrm{T}-4 \mathrm{~b}-\mathrm{G}$ & 0.8348 & 0.7857 & 0.8080 & 0.7315 & 0.326 & 0.393 & $0.018^{\mathrm{b}}$ & 0.413 \\
\hline $\mathrm{T}-4 \mathrm{~b}-\mathrm{T}$ & 0.0907 & 0.0429 & 0.0906 & 0.1019 & 0.187 & 0.997 & 0.729 & 0.153 \\
\hline C-4a-G & 0.0627 & 0.1429 & 0.0978 & 0.1667 & $0.023^{\mathrm{b}}$ & 0.112 & $0.001^{\mathrm{c}}$ & 0.670 \\
\hline T-4a-G & 0.0062 & 0.0286 & 0.0036 & - & 0.092 & 0.653 & - & - \\
\hline C- $4 b-G$ & 0.0031 & - & - & - & - & - & - & - \\
\hline C-4a-T & 0.0025 & - & - & - & - & - & - & - \\
\hline
\end{tabular}

aHaplotype of $e N O S$ (-786T $>$ C, 4a4b, 894G $>$ T). Significant $\mathrm{p}$-values: ${ }^{\mathrm{b}} \mathrm{p}<0.05$ and ${ }^{\mathrm{c}} \mathrm{p}<0.005$. P1, p-value of controls without DM vs. controls with DM; P2, p-value of controls without DM vs. CAD patients without DM; P3, p-value of controls without DM vs. CAD patients with DM; P4, p-value of controls with DM vs. CAD patients with DM.

(including 35 T2DM patients) are described in Table I. No significant differences in gender and age existed between the subgroups. Hypertension was higher in the controls and the CAD group with DM ( $\mathrm{p}<0.05)$. In addition, smoking and hyperlipidemia were significantly higher in the control group with DM compared to the control group without DM $(\mathrm{p}<0.05)$ in contrast to the comparison in the CAD subgroups.

Three polymorphisms of the eNOS gene, -786T $>\mathrm{C}, 4 \mathrm{a} 4 \mathrm{~b}$ and $894 \mathrm{G}>\mathrm{T}$, were investigated. The genotype distributions in the CAD patients and controls are shown in Table II. The genotype frequencies for all of the polymorphisms were in accordance with Hardy-Weinberg equilibrium in the cases and control groups. We subgrouped the controls and CAD patients with regard to T2DM status and evaluated for any association with particular genotypes. Genotype distributions of $-786 \mathrm{~T}>\mathrm{C}, 4 \mathrm{a} 4 \mathrm{~b}$ and $894 \mathrm{G}>\mathrm{T}$ in the subgroups of the CAD patients and controls are shown in Table II. The distribution of the eNOS -786T >C genotypes and allele frequencies in both the CAD patients and controls showed significant associations between the $-786 \mathrm{~T}>\mathrm{C}$ polymorphism and the risk of T2DM. Additionally, the allele frequencies of eNOS 4a $4 \mathrm{~b}$ of the controls and CAD patients showed significant differences 
with regard to T2DM. No predisposition to T2DM was found for the $894 \mathrm{G}>\mathrm{T}$ polymorphism in either the controls or CAD patients.

Furthermore, we performed haplotype analyses for the control and CAD patient subgroups according to the T2DM status, and the results are shown in Table III. The most common haplotype of all of the subgroups was -786T-4b-894G. The eNOS -786C-4a-894G haplotype was found more commonly in the DM subgroups from both the CAD patients and controls compared to the non-diabetic subgroups, suggesting that this haplotype has a significant association with T2DM. Furthermore, the association was stronger in the CAD patients than in the controls. Also, the haplotype frequencies of -786T4b-894G were significantly different between the non-diabetic controls and diabetic CAD patients $(\mathrm{p}=0.018)$.

\section{Discussion}

In the present study, we analyzed the associations of the $e N O S$ $-786 \mathrm{~T}>\mathrm{C}$, 4a 4b and 894G>T polymorphisms with CAD and T2DM by subgrouping both the CAD patients and controls by T2DM status. Our findings suggest that the genotypes and haplotypes of these three eNOS polymorphisms are not independent predisposition factors to CAD, but are associated with T2DM in the Korean population. The allele frequencies of both $-786 \mathrm{C}$ and $4 \mathrm{a}$ were significantly associated with T2DM, but not with CAD per se, whereas the eNOS $894 \mathrm{G}>\mathrm{T}$ polymorphism was not an independent risk factor for either CAD or DM (Table II).

The -786T $>$ C mutation in the promoter region of $e N O S$ results in the inhibition of $e N O S$ promoter activity (11), leading to endothelial dysfunction by reduced NO production in blood vessels. The intron 4 variable number of tandem repeats polymorphism, in which alleles contain either 4 repeats $(4 a)$ or 5 repeats (4b), also affects basal NO production in the blood vessels (19). The mutation of $e N O S$ 894G $>\mathrm{T}$ produces a missense Glu298Asp eNOS, which may alter eNOS activity by a conformational change or by protease-mediated cleavage $(20,21)$. Although numerous studies have examined the association of $e N O S$ genotypes to cardiovascular diseases in different populations, the influences of $e N O S$ polymorphisms on the risk of cardiovascular diseases are not consistent. In our previous study, we did not find associations of the eNOS polymorphisms, $-786 \mathrm{~T}>\mathrm{C}, 4 \mathrm{a} 4 \mathrm{~b}$ and $894 \mathrm{G}>\mathrm{T}$, with $\mathrm{CAD}$ in the Korean population, but $-786 \mathrm{~T}>\mathrm{C}$ and $4 \mathrm{a} 4 \mathrm{~b}$ had predispositions to CAD after adjusting for other conventional cardiovascular risk factors (22). Consistent with this, no significant difference in $e N O S$ genotype distributions of $-786 \mathrm{~T}>\mathrm{C}, 4 \mathrm{a} 4 \mathrm{~b}$ or $894 \mathrm{G}>\mathrm{T}$ was observed with CAD in the present study among Koreans without adjusting for risk factors and neither did an additional analysis of haplotypes of three-loci polymorphisms produce any association with CAD (data not shown).

Since T2DM is a known risk factor for cardiovascular diseases associated with endothelial dysfunction (23), we further analyzed the genotype distributions of $e N O S$ polymorphisms in the CAD patients and control subjects after dividing each group according to T2DM status. To our knowledge, this is the first report to determine the association of CAD with three eNOS polymorphisms by comparing four subgroups divided according to both CAD and T2DM. Zhang et al (24) examined $e N O S$ variants and the risks of coronary heart disease among diabetic men in the US and found that the genotype distributions of $-786 \mathrm{~T}>\mathrm{C}$ and $894 \mathrm{G}>\mathrm{T}$ were not significantly different among the men with or without coronary heart disease, but non-diabetic samples were not included in their study. We observed that the allele frequencies of $e N O S$ $-786 \mathrm{~T}>\mathrm{C}, 4 \mathrm{a} 4 \mathrm{~b}$ and $894 \mathrm{G}>\mathrm{T}$ were not significantly different between the non-diabetic CAD patients and the non-diabetic controls (Table II). However, statistically significant associations in the allele distributions of $-786 \mathrm{~T}>\mathrm{C}$ and $4 \mathrm{a} 4 \mathrm{~b}$ were found between the diabetic control and non-diabetic control subjects, although the T2DM sample size was relatively small. In addition, heterozygotes and mutant homozygotes of $e N O S-786 \mathrm{~T}>\mathrm{C}$ and $4 \mathrm{a} 4 \mathrm{~b}$ were significantly prevalent in the diabetic CAD patients compared to the non-diabetic control group. Furthermore, when we re-organized the same population regarding the presence of T2DM, the heterozygotes and the mutant homozygotes of $e N O S-786 \mathrm{~T}>\mathrm{C}$ and $4 \mathrm{a} 4 \mathrm{~b}$ were also significantly frequent in the group with T2DM (-786TT vs. $-786 \mathrm{TC}+\mathrm{CC}$; OR=2.32, $95 \%$ CI $1.299-4.137$ and $4 \mathrm{~b} 4 \mathrm{~b}$ vs. $4 a 4 b+4 a 4 a ; O R=2.28,95 \%$ CI 1.293-4.022). Therefore, our findings suggest that the $e N O S-786 \mathrm{~T}>\mathrm{C}$ and $4 \mathrm{a} 4 \mathrm{~b}$ polymorphisms are associated with predisposition to T2DM, but not to CAD, while no correlation exists between the eNOS 894G>T genotype and CAD or T2DM.

Results regarding the role of $e N O S$ polymorphisms in the predisposition to T2DM are limited and conflicting. Pulkkinen and colleagues (25) found that the $4 \mathrm{a} 4 \mathrm{~b}$ and $894 \mathrm{G}>\mathrm{T}$ polymorphisms were not associated with T2DM or coronary heart disease in Finnish individuals. By contrast, associations of 4a4b (26) and 894G>T (27) polymorphisms with T2DM were demonstrated in Polish and Italian populations, respectively. In a recent publication by Rittig et al (28), the independent association of the $4 \mathrm{a} 4 \mathrm{~b}$, but not $786 \mathrm{~T}>\mathrm{C}$ and $894 \mathrm{G}>\mathrm{T}$ polymorphisms, with disturbed endothelial function in a German population with increased risk to develop T2DM was reported. Our present study suggests an association of $e N O S-786 \mathrm{~T}>\mathrm{C}$ and $4 \mathrm{a} 4 \mathrm{~b}$, but not $894 \mathrm{G}>\mathrm{T}$, genotypes with T2DM. Therefore, further comprehensive studies with uniformly standardized criteria devoid of undetected confounding factors are required to establish a firm conclusion.

Recently, haplotype analysis of single nucleotide polymorphism (SNP) markers of genes has been recognized to provide better information than SNP analysis (29). Rios et al (30) analyzed the haplotypes of two loci, $-786 \mathrm{~T}>\mathrm{C}$ and $894 \mathrm{G}>\mathrm{T}$, with the CAD risk and reported that the frequency of the wildtype haplotype, -786T-894G, was decreased in CAD patients. A recent report studying the effects of $e N O S$ polymorphisms and smoking on CAD in Brazilians showed that the frequency of the -786C-4a-894G haplotype was higher in CAD patients, whereas that of -786T-4a-894G haplotype was lower, but associations were not present for non-smoking CAD patients (31). In the present study, three-loci haplotypes of eNOS, -786T $>\mathrm{C}$, $4 \mathrm{a} 4 \mathrm{~b}$ and $894 \mathrm{G}>\mathrm{T}$, were analyzed for their associations with CAD and T2DM, and we found that no haplotype had any predisposition for CAD (data not shown). Therefore, these genotype and haplotype analyses suggest that the eNOS polymorphisms are unlikely to exhibit significant additive effects on predisposition to CAD in the Korean population. However, we cannot exclude the possibility that a marginal association 
of eNOS polymorphisms with CAD is masked by other unadjusted risk factors.

Two haplotypes of eNOS polymorphisms affected the susceptibility to T2DM (Table III). The frequency of wildtype haplotype, -786T-4b-894G, was significantly lower in the diabetic CAD patients compared to the non-diabetic controls. A positive association of the $-786 \mathrm{~T}-4 \mathrm{~b}-894 \mathrm{G}$ haplotype between the non-diabetic and diabetic control groups was also observed after re-organizing the population in regard to T2DM (data not shown). In addition, we observed that the frequency of the -786C-4a-894G haplotype varied significantly between the groups. Notably, a significant association was present between the non-diabetic and diabetic controls, indicating that this haplotype is susceptible to T2DM, and the association was even stronger when we compared the non-diabetic controls to the diabetic CAD patients. The haplotype frequency of -786C-4a-894G was also significantly different between the non-diabetic and diabetic groups (data not shown), indicating that this haplotype is indeed susceptible to T2DM. Therefore, the $-786 \mathrm{C}-4 \mathrm{a}-894 \mathrm{G}$ haplotype is likely an independent risk factor for T2DM. While further studies with a larger sample size and with a random population are required to reach a firm conclusion, as far as we know, this is the first study to identify susceptible and protective haplotypes of eNOS loci to DM per se, although eNOS haplotype analyses for diabetic complications are available $(32,33)$.

In conclusion, our finding suggests that the eNOS $-786 \mathrm{~T}>\mathrm{C}$ and $4 \mathrm{a} 4 \mathrm{~b}$ polymorphisms and the $-786 \mathrm{C}-4 \mathrm{a}-894 \mathrm{G}$ haplotype are risk factors for T2DM particularly in CAD patients, whereas the haplotype of $-786 \mathrm{~T}-4 \mathrm{~b}-894 \mathrm{G}$ has a protective effect against the development of T2DM. Further studies involving larger and varied populations would be of great value to firmly conclude the correlation between eNOS polymorphisms and T2DM and to establish an intervention in the development of diabetes for those with the mutant eNOS genotypes.

\section{Acknowledgements}

This study was supported, in part, by the Korea Research Foundation Grant, funded by the Korean Government (KRF-2008-521-E00121), and partly supported by the Priority Centers Program through the National Research Foundation of Korea (NRF), funded by the Ministry of Education, Science and Technology (2009-0093821).

\section{References}

1. Kuvin JT, Patel AR, Sliney KA, Pandian NG, Rand WM, Udelson JE and Karas RH: Peripheral vascular endothelial function testing as a noninvasive indicator of coronary artery disease. J Am Coll Cardiol 38: 1843-1849, 2001.

2. Heitzer T, Schlinzig T, Krohn K, Meinertz T and Munzel T: Endothelial dysfunction, oxidative stress, and risk of cardiovascular events in patients with coronary artery disease. Circulation 104: 2673-2678, 2001.

3. Faxon DP, Fuster V, Libby P, Beckman JA, Hiatt WR, Thompson RW, Topper JN, Annex BH, Rundback JH, Fabunmi RP, Robertson RM and Loscalzo J: American Heart Association. Atherosclerotic vascular disease conference: writing group III: pathophysiology. Circulation 109: 2617-2625, 2004.

4. Puddu P, Cravero E, Puddu GM and Muscari A: Genes and atherosclerosis: at the origin of the predisposition. Int J Clin Pract 59: 462-472, 2005.
5. Wolf A, Zalpour C, Theilmeier G, Wang BY, Ma A, Anderson B, Tsao PS and Cooke JP: Dietary 1-arginine supplementation normalizes platelet aggregation in hypercholesterolemic humans. J Am Coll Cardiol 29: 479-485, 1997.

6. Kubes P, Suzuki M and Granger DN: Nitric oxide: an endogenous modulator of leukocyte adhesion. Proc Natl Acad Sci USA 88: 4651-4655, 1991

7. Garg UC and Hassid A: Nitric oxide-generating vasodilators and 8-bromo-cyclic guanosine monophosphate inhibit mitogenesis and proliferation of cultured rat vascular smooth muscle cells. J Clin Invest 83: 1774-1777, 1989.

8. Böger RH, Bode-Böger SM, Mügge A, Kienke S, Brandes R, Dwenger A and Frölich JC: Supplementation of hypercholesterolaemic rabbits with L-arginine reduces the vascular release of superoxide anions and restores NO production. Atherosclerosis 117: 273-284, 1995.

9. Hogg N, Kalyanaraman B, Joseph J, Struck A and Parthasarathy S: Inhibition of low-density lipoprotein oxidation by nitric oxide. Potential role in atherogenesis. FEBS Lett 334: 170-174, 1993.

10. Wilcox JN, Subramanian RR, Sundell CL, Tracey WR, Pollock JS, Harrison DG and Marsden PA: Expression of multiple isoforms of nitric oxide synthase in normal and atherosclerotic vessels. Arterioscler Thromb Vasc Biol 17: 2479-2488, 1997.

11. Nakayama $M$, Yasue $H$, Yoshimura M, Shimasaki $Y$, Kugiyama K, Ogawa H, Motoyama T, Saito Y, Ogawa Y, Miyamoto Y and Nakao K: T-786-->C mutation in the 5'-flanking region of the endothelial nitric oxide synthase gene is associated with coronary spasm. Circulation 99: 2864-2870, 1999.

12. Yoshimura M, Yasue H, Nakayama M, Shimasaki Y, Sumida H, Sugiyama S, Kugiyama K, Ogawa H, Ogawa Y, Saito Y, Miyamoto Y and Nakao K: A missense Glu298Asp variant in the endothelial nitric oxide synthase gene is associated with coronary spasm in the Japanese. Hum Genet 103: 65-69, 1998.

13. Wang XL, Sim AS, Badenhop RF, McCredie RM and Wilcken DE: A smoking-dependent risk of coronary artery disease associated with a polymorphism of the endothelial nitric oxide synthase gene. Nat Med 2: 41-45, 1996.

14. Casas JP, Cavalleri GL, Bautista LE, Smeeth L, Humphries SE and Hingorani AD: Endothelial nitric oxide synthase gene polymorphisms and cardiovascular disease: a HuGE review. Am J Epidemiol 164: 921-935, 2006.

15. Pieper GM: Review of alterations in endothelial nitric oxide production in diabetes: protective role of arginine on endothelial dysfunction. Hypertension 31: 1047-1060, 1998.

16. Wilson PW: Established risk factors and coronary artery disease: the Framingham Study. Am J Hypertens 7: S7-S12, 1994.

17. Chobanian AV, Bakris GL, Black HR, Cushman WC, Green LA, Izzo JL Jr, Jones DW, Materson BJ, Oparil S, Wright JT Jr and Roccella EJ: The seventh report of the Joint National Committee on Prevention, Detection, Evaluation, and Treatment of High Blood Pressure: the JNC 7 report. JAMA 289: 2560-2572, 2003.

18. American Diabetes Association: Diagnosis and classification of diabetes mellitus. Diabetes Care 27: S5-S9, 2004.

19. Wang XL, Mahaney MC, Sim AS, Wang J, Wang J, Blangero J, Almasy L, Badenhop RB and Wilcken DE: Genetic contribution of the endothelial constitutive nitric oxide synthase gene to plasma nitric oxide levels. Arterioscler Thromb Vasc Biol 17: 3147-3153, 1997.

20. Cooke JP: Role of nitric oxide in progression and regression of atherosclerosis: West J Med 164: 419-424, 1996.

21. Tesauro M, Thompson WC, Rogliani P, Qi L, Chaudhary PP and Moss J: Intracellular processing of endothelial nitric oxide synthase isoforms associated with differences in severity of cardiopulmonary diseases: cleavage of proteins with aspartate vs. glutamate at position 298. Proc Natl Acad Sci USA 97: 2832-2835, 2000.

22. Kim IJ, Bae J, Lim SW, Cha DH, Cho HJ, Kim S, Yang DH, Hwang SG, Oh D and Kim NK: Influence of endothelial nitric oxide synthase gene polymorphisms $(-786 \mathrm{~T}>\mathrm{C}, 4 \mathrm{a} 4 \mathrm{~b}, 894 \mathrm{G}>\mathrm{T})$ in Korean patients with coronary artery disease. Thromb Res 119: 579-585, 2007.

23. McVeigh GE, Brennan GM, Johnston GD, McDermott BJ, McGrath LT, Henry WR, Andrews JW and Hayes JR: Impaired endothelium-dependent and independent vasodilation in patients with type 2 (non-insulin-dependent) diabetes mellitus. Diabetologia 35: 771-776, 1992.

24. Zhang C, Lopez-Ridaura R, Hunter DJ, Rifai N and Hu FB: Common variants of the endothelial nitric oxide synthase gene and the risk of coronary heart disease among US diabetic men. Diabetes 55: 2140-2147, 2006. 
25. Pulkkinen A, Viitanen L, Kareinen A, Lehto S, Vauhkonen I and Laakso M: Intron 4 polymorphism of the endothelial nitric oxide synthase gene is associated with elevated blood pressure in type 2 diabetic patients with coronary heart disease. J Mol Med 78: 372-379, 2000

26. Ksiazek P, Wojewoda P, Muc K and Buraczynska M: Endothelial nitric oxide synthase gene intron 4 polymorphism in type 2 diabetes mellitus. Mol Diagn 7: 119-123, 2003.

27. Monti LD, Barlassina C, Citterio L, Galluccio E, Berzuini C, Setola E, Valsecchi G, Lucotti P, Pozza G, Bernardinelli L, Casari G and Piatti P: Endothelial nitric oxide synthase polymorphisms are associated with type 2 diabetes and the insulin resistance syndrome. Diabetes 52: 1270-1275, 2003.

28. Rittig K, Holder K, Stock J, Tschritter O, Peter A, Stefan N, Fritsche A, Machicao F, Häring HU and Balletshofer B: Endothelial NO-synthase intron 4 polymorphism is associated with disturbed in vivo nitric oxide production in individuals prone to type 2 diabetes. Horm Metab Res 40: 13-17, 2008.

29. Lee JE, Choi JH, Lee JH and Lee MG: Gene SNPs and mutations in clinical genetic testing: haplotype-based testing and analysis. Mutat Res 573: 195-204, 2005.
30. Rios DL, Callegari-Jacques SM and Hutz MH: Endothelial nitric oxide synthase and fractalkine chemokine receptor polymorphisms on angiographically assessed coronary atherosclerosis. Clin Chim Acta 362: 138-146, 2005.

31. Rios DL, D'Onofrio LO, Souza JK, Queiroz AM, Raduy-Maron L, Silva-Neto N, Carvalho HG, Santos-Filho A and Galvão-Castro B: Smoking-dependent and haplotype-specific effects of endothelial nitric oxide synthase gene polymorphisms on angiographically assessed coronary artery disease in Caucasian- and African-Brazilians. Atherosclerosis 193: 135-141, 2007.

32. Sandrim VC, de Syllos RW, Lisboa HR, Tres GS and Tanus-Santos JE: Endothelial nitric oxide synthase haplotypes affect the susceptibility to hypertension in patients with type 2 diabetes mellitus. Atherosclerosis 189: 241-246, 2006.

33. Sandrim VC, de Syllos RW, Lisboa HR, Tres GS and Tanus-Santos JE: Influence of eNOS haplotypes on the plasma nitric oxide product concentrations in hypertensive and type 2 diabetes mellitus patients. Nitric Oxide 16: 348-355, 2007. 